\title{
Accumulation of Heavy Metal Ions by Eichhornia Crassipes from Battery Industry Effluent under the Influence of Cattle Manure
}

\author{
Dineshkumar Myilsamy ${ }^{1}$, Sivalingam Angamuthu², Thirumarimurugan Marimuthu ${ }^{3}$ \\ ${ }^{1}$ Research Scholar, Department of Chemical Engineering, Coimbatore Institute of Technology, \\ Coimbatore, Tamil Nadu, India - 641014. \\ kdineshd@gmail.com \\ ${ }^{2}$ Associate Professor, Department of Chemical Engineering, Coimbatore Institute of Technology, \\ Coimbatore, Tamil Nadu, India - 641014. \\ as.sabhari@gmail.com \\ ${ }^{3}$ Professor, Department of Chemical Engineering, Coimbatore Institute of Technology, \\ Coimbatore, Tamil Nadu, India - 641014. \\ thirumarimurugan@gmail.com
}

\begin{abstract}
Phytoremediation, an emerging technology which uses plants to remove contaminants of concern (COC) such as organic and inorganic compounds especially heavy metals (HM). The present study focuses on assessing the toxicity of heavy metals available in effluents discharged from industries and the accumulation ability of an aquatic plant, Eichhornia crassipes (water hyacinth). Phytoremedial potential of $E$. Crassipes and HM interaction between soil and water were evaluated in the present study under the presence of cow dung manure as an enhancer. Heterogenous accumulation of metal ions were found in the plant. Heavy metal concentration in plant parts were varied for roots and shoots. The concentration of $\mathrm{HM}$ ions in the plant parts were varied from root to shoot. Value of translocation factor (TF) was found to be in the region $0.5-0.8$, with $\mathrm{Fe}$ has low $(0.51)$ and $\mathrm{Pb}$ has high $(0.77)$, bioconcentration factor (BCF) were in the order of $\mathrm{Ar}>\mathrm{Ca}>\mathrm{Zn}>\mathrm{Fe}>\mathrm{Pb}$ at both roots and shoots. Transposition factor ( $\mathrm{TrF})$ of all $\mathrm{HM}$ ions were $>1.5$ except for $\mathrm{Zn}$ (1.21). E. Crassipes was found to accumulate a large amount of HM ions and could be used for efficient treatment of contaminated water.
\end{abstract}

\section{Keywords}

heavy metal; Eichhornia crassipes; battery effluent; transposition factor; Coimbatore

\section{Academic Discipline And Sub-Disciplines}

Environmental;waste water treatment; phytoremediation;

\section{SUBJECT CLASSIFICATION}

Remeditaion of heavy metals ion in effluent using plants

\section{TYPE (METHOD/APPROACH)}

Experimentation and analysis

\section{INTRODUCTION}

Heavy metal contamination from industrial dicharges as effluent and sludge to environment is a key risk for human beings as it enters into food chains and causes a serious threat to living beings [1]. Essential heavy metals i.e., calcium, magnesium, zinc, cobalt, potassium etc. which are found to be toxic at excess level whereas non-essential elements i.e., chromium, lead, arsenic, cadmium etc. were toxic even at low concentrations [2]. Remediation and removal are the two important strategies used in the treatment of contaminants. Eliminating and remediating heavy metals from the environment is the toughest challenge faced by the researchers since the start of $21^{\text {st }}$ century. Increasing ecological and health problems from conventional methods, it is important to turn out for effective and affordable method for the treatment of heavy metal pollution in environment [3]. In order to treat these pollutions, technologies such as precipitation, filtration, coagulation, adsorption, ion exchange and electrocoagulation have been developed and found to be expensive and produces sludge as waste product which affects the environment $[4,5]$. In other hand phytoremediation is found to be more success with both economic and environmental wise. Phytoremediation is a method of using plant to uptake contaminants from water and soil [6-8]. Since it is more of biotechnology approach and low operational cost, it received a tremendous attention in recent years. Studies show that the ability of aquatic plant to remediate environment from heavy metal pollution at both living and dead conditions were higher than terrestrial plants [9, 10]. Plants which are seen in streams, coastal zones, drainage and everglades had high ability to remove heavy metal. Various species of aquatic plants such as Myriophyllum spicatum, Potamogeton lucens, Salvinia herzogoi, Cabomba sp., Ceratophyllum demersum, Lemna minor, Lemna gibba, Lemna aequinoctialis, Spirodela polyrhiza, Azolla filiculoides, Azolla caroliniana, Azolla pinnata and Pistia stratiotes have been used in phytoremediation process [10, 11].

E. Crassipes, (water hyacinth) a free floating aquatic plant from Pontederiaceae family, which is very common in India and available largely in the lakes, irrigation ponds and drainage systems. Due to high growth rate and transpiration rate it is 
considered as harmful plant $[12,13]$. It has been studied on the removal of heavy metal ions presents in water and found to have the potential to accumulate large metal ions in its root [14]. Because of its high biomass, tolerance and heavy metal uptake capacity it could be used in the water treatment process. This study was conducted to determine the heavy metal concentration in plant parts (root and soil), soil, effluent and the detailed investigation on heavy metal removal by means of translocation, bioconcentration and transposition factor.

\section{MATERIALS AND METHODS}

\section{Experimental set-up}

Aquatic plant, Water hyacinth (E. Crassipes) was collected from the Singanallur Lake, $\left(10^{\circ} 59^{\prime} 20.59^{\prime \prime} \mathrm{N} 77^{\circ} 1 ' 21.88^{\prime \prime} \mathrm{E}\right)$ located in Coimbatore, Tamil Nadu, India which is available nearest to the experimental site. Collected plants were washed thoroughly with de-ionized water and transplanted to a plastic container which contains Hoagland solution to enrich the nutrient condition to the plant. Each three days Hoagland solution in the container were replaced with the new solution for 30days. Since E. Crassipes populates through the interconnected shoot parts, newly grown plants were collected and used for the removal of heavy metal ions from battery industry effluent.

Newly collected plants were placed in experimental container in presence of effluent and uncontaminated red soil which is found to improve plant growth. At initial condition, the ratio of effluent and soil in the experimental container was kept 1:1. Sample solutions were collected at an interval of 5 days' over a period of 25 days for the determination of metal concentrations in the container. Cow dung manure (CDM) was added to the experimental container during the interval period. Loss of effluent was observed due to plant uptake and evaporation. These obstacles were ignored in the experiment to maintain the condition of the setup. All the experimental sets were maintained in triplicate.

\section{Heavy metal analysis in plants}

Plants were harvested at an interval of 5 days after the exposure with effluent. Harvested plants were washed twice with tap water and by de-ionized water. After thorough wash, these plants were separated into roots and shoots. Separated plant parts were dried in an oven at $80{ }^{\circ} \mathrm{C}$ for 90 minutes to remove all the moisture content in plants. Dried samples were grounded to powder and digested with $\mathrm{Con} . \mathrm{HNO}_{3}$ and $\mathrm{Con}_{\mathrm{HClO}} \mathrm{H}_{4}$ in the ratio of 2:1. It is then diluted with $100 \mathrm{ml}$ deionized water. The diluted solution was analyzed for heavy metals concertation with atomic absorption spectrophotometry (AAS, PerkinElmer) [15]. Initial heavy metal concentrations in effluent were analyzed and mentioned in the table 1.

Table 1. Initial heavy metal concentration in effluent

\section{Parameters analyzed}

\begin{tabular}{|c|c|c|}
\hline S. No & Heavy Metal & Concentration (ppm) \\
\hline 1. & Arsenic (Ar) & 33.52 \\
\hline 2. & Lead (Pb) & 25.279 \\
\hline 3. & Calcium (Ca) & 26.562 \\
\hline 4. & Iron (Fe) & 177.333 \\
\hline 5. & Zinc (Zn) & 41.964 \\
\hline
\end{tabular}

Factors such as translocation (TF) and bioconcentration factor (BCF) in phytoremediation process were calculated. Apart from that contaminants settled into the soil from effluent were mentioned as transposition factor (TrF). It is a newly formed factor which enables us to get into the insight of heavy metal contaminants settled in soil.

\section{Translocation Factor (TF)}

It is common to understand that the plant translocates heavy metal ions into shoot via root parts of the system. The translocation of contaminants from root to shoot were calculated. In general, plants with $>1$ TF value is termed as phytoextractor. It is calculated by the given formula [16]:

$$
T F=\frac{\text { Concentration in shoot }(p p m)}{\text { Concentration in root }(\text { ppm })}
$$

\section{Bioconcentration Factor (BCF)}

Concentration of heavy metal ions in plants parts and in effluent were used to calculate bioconcentration factor. When the plants possess a BCF value of $>1$, then the plant can be called as hyperaccumulator plant. Thus, it is calculated by the following formula [16]: 


\section{Transposition Factor (TrF)}

Metal concentration in plant were excluded for the calculation of TrF, as it depends upon the contaminants transferred from effluent to soil. It can be calculated as follows:

$\operatorname{Tr} F=\frac{\text { Concentration in soil }(\mathrm{ppm})}{\text { Concentration in ef fleunt }(\mathrm{ppm})}$

\section{Quality Assurance}

All the chemicals used in the experiment were analytical grade. $\mathrm{pH}$ of the effluent was maintained daily in the range of $6-$ 6.5 using $1.0 \mathrm{M} \mathrm{HCl}$ and $\mathrm{NaOH}$ to yield a better removal of contaminants. Experimental setup and the datas obtained were triplicated to minimize the error for quality control.

\section{RESULTS}

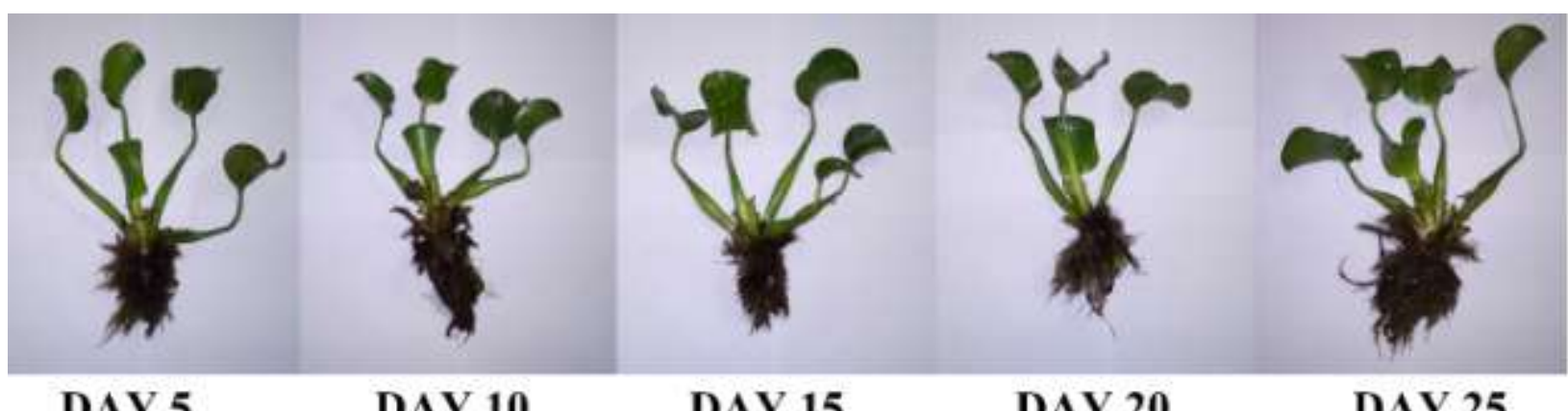
DAY 5
DAY 10
DAY 15
DAY 20
DAY 25

Fig. 1. Effect of heavy metal ions on plants root at each interval.

Effect of heavy metal ions on the aquatic plant were indicated in the above figure 1 . It explains that ${ }_{2}$ due to toxicity of heavy metals, root parts of the plants were affected at initial stages but recovered after a period. The same phenomena was observed in the accumulation of heavy metal ions by the plant specified in the table 2 .

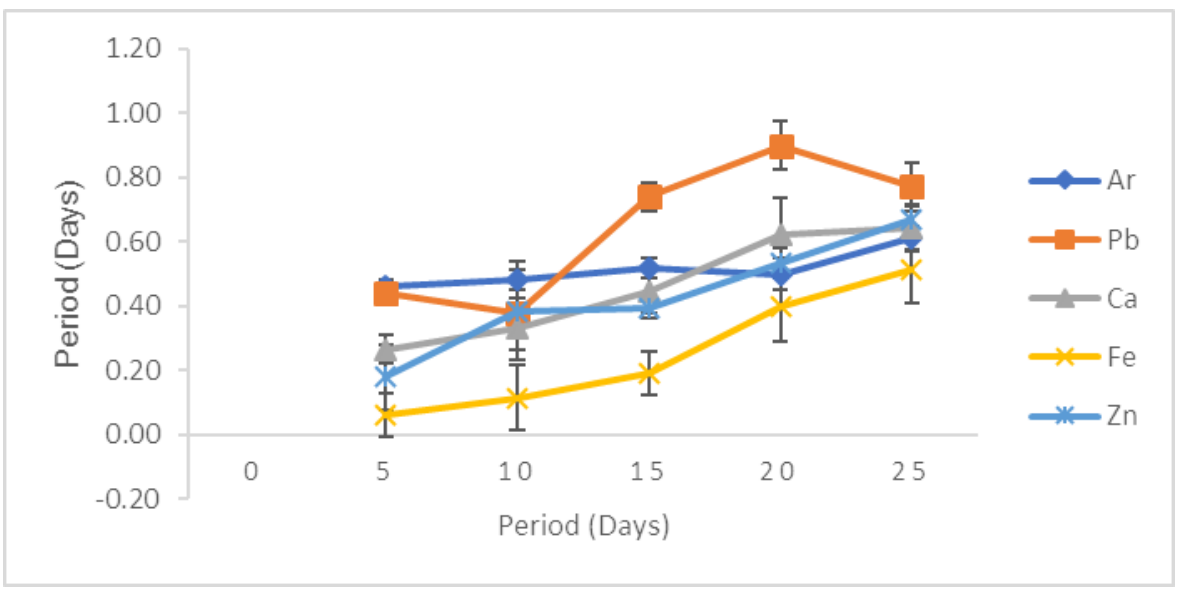

Fig. 2. Translocation factor of plant from root to shoot metal concentration

In general, contaminants accumulated in the shoots transferred through roots. Amount of contaminants translocated to the shoots is called as TF from the above figure 2 it is understood that Pb possess high TF value even though it is found to be decreased at later stages. All other metal ions show a gradual increase of TF value with the accumulation of heavy metal ions. TF of metal ions is ordered as follows $\mathrm{Pb}>\mathrm{Zn}>\mathrm{Ca}>\mathrm{Ar}>\mathrm{Fe}$. 


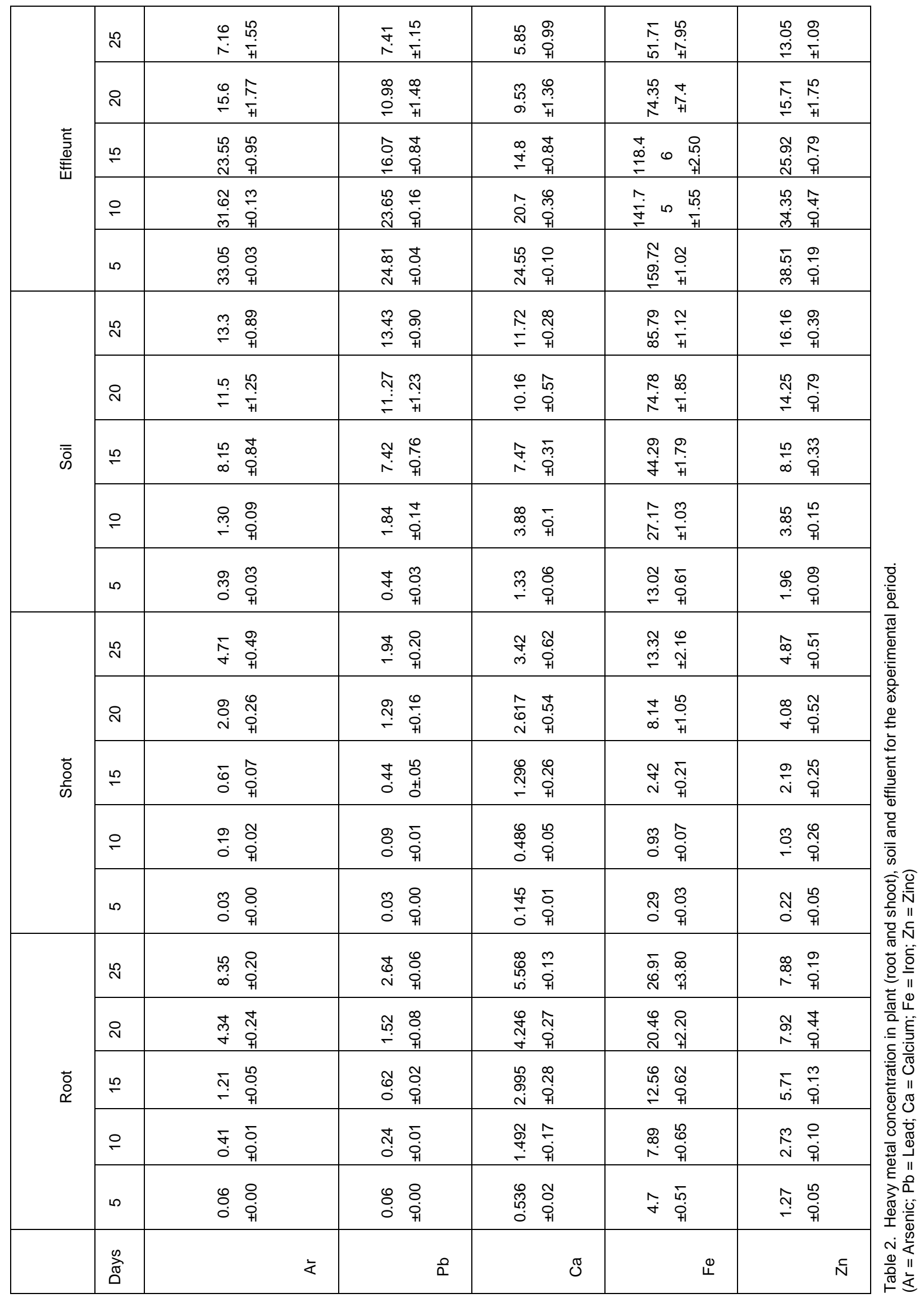




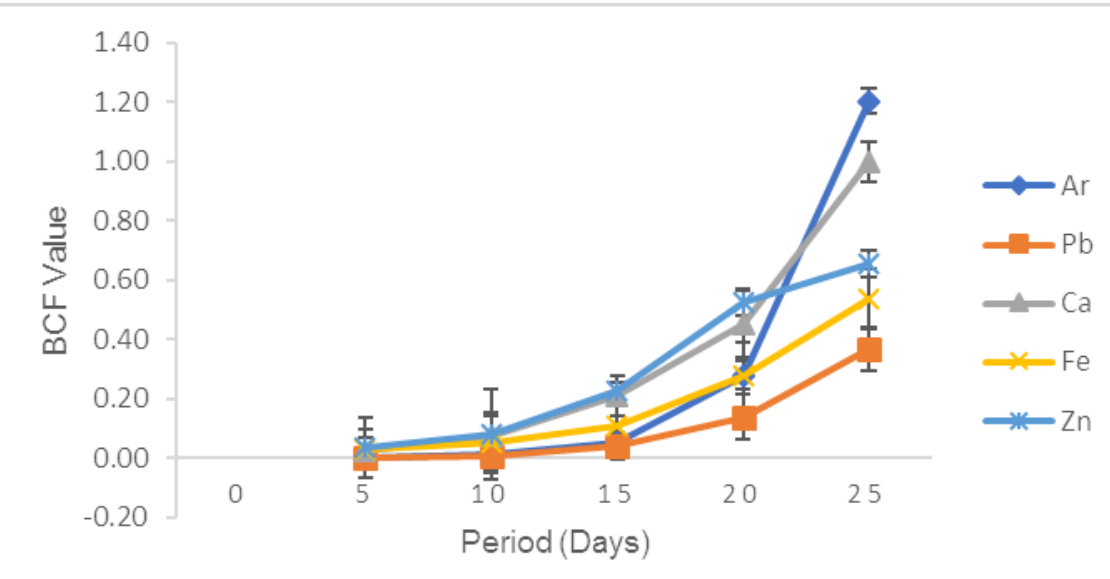

Fig. 3. BCF value of root from effluent to shoot metal concentration

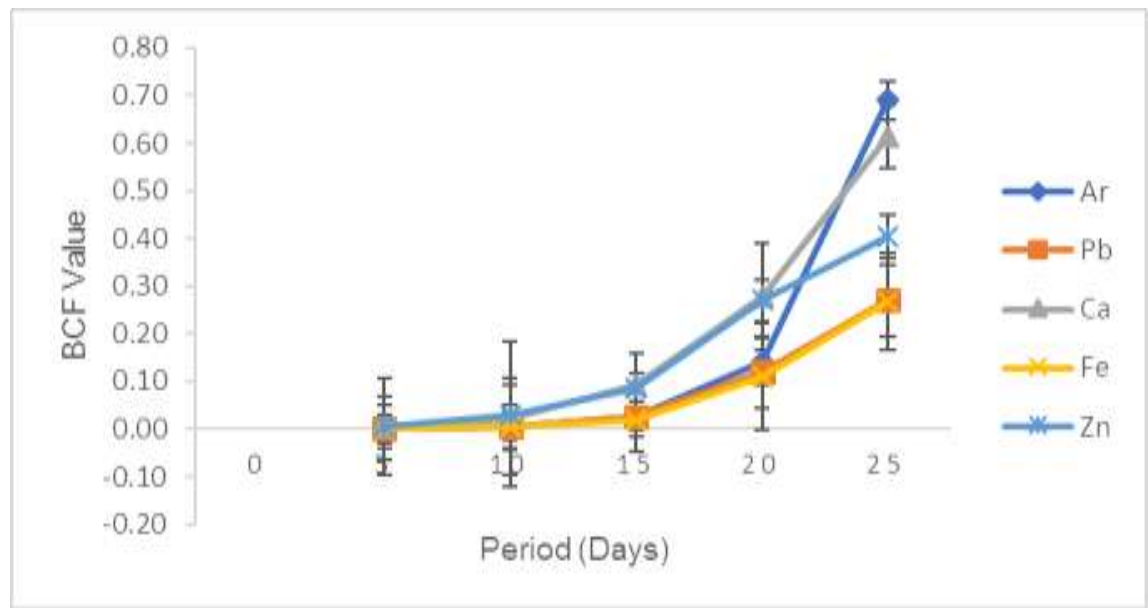

Fig. 4. BCF value of shoot from effluent to shoot metal concentration

BCF value of root and shoot were illustrated in the Fig. 3. and 4. In both cases Ar was found to have high BCF value with 1.21 and 0.69 for root and shoot respectively. Both the figure forms similar sketch only a small deviation between Fe and $\mathrm{Pb}$. It also expresses that root parts of the plant translocates a small amount of $\mathrm{HM}$ ions from its accumulation. BCF value of HM's in root and shoot for heavy metal ions is ordered as follows: $\mathrm{Ar}>\mathrm{Ca}>\mathrm{Zn}>\mathrm{Fe}>\mathrm{Pb}$.

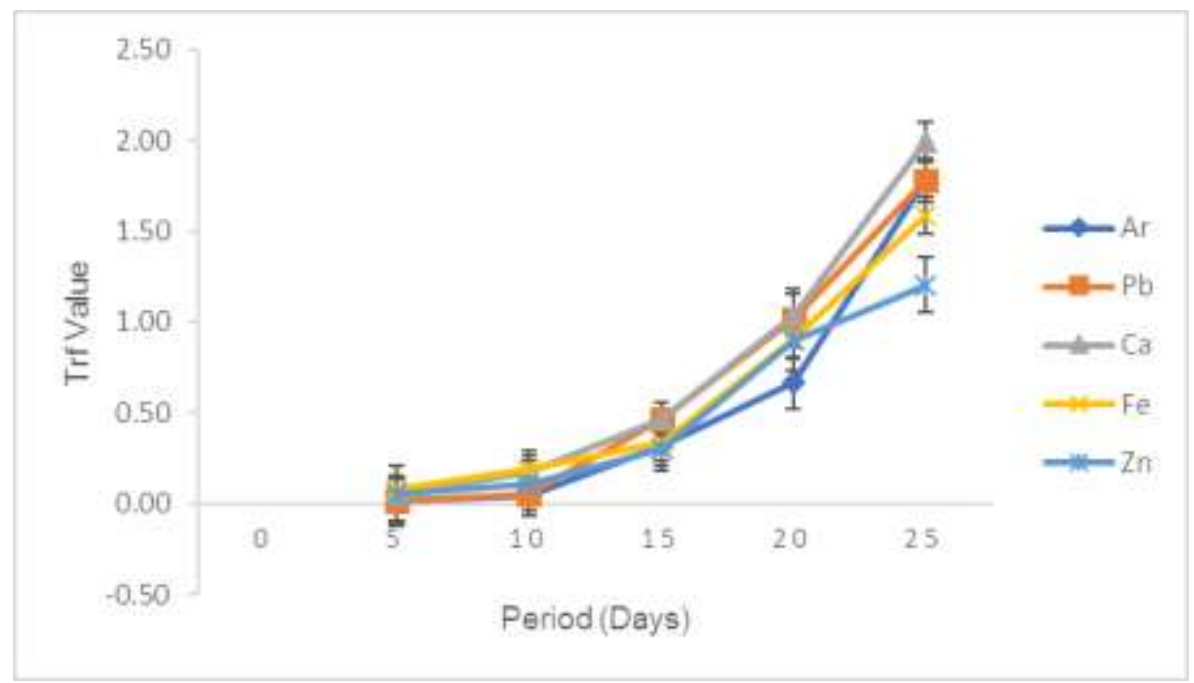

Fig. 5. Transposition factor of heavy metal ions from soil to effleunt

It is commonly known that in any medium transferred from higher to lower concentration level and it is understood that heavy metal ions in the contaminated medium might transferred to uncontaminated medium. The contaminants in effluent transferred to soil is calculated by the newly framed factor, known as transposition factor (TrF). Fig. 5. obtains $>1$ value for 
all the metal ions. It indicates that the metal ions were continuously settled into soil and the Fig. 5. indicates a gradual increase of TrF after the 10th day of experimental period.

\section{DISCUSSIONS}

Root pressure and leaf transpiration are the two-important process controls the translocation of metal ions from root to shoot $[16,17]$. Due to physiological resistances, plants might not be able to accumulate large amount of metal ions [18]. In the present study, metal ions such as $\mathrm{Ar}, \mathrm{Pb}, \mathrm{Ca}, \mathrm{Fe}$ and $\mathrm{Zn}$ concentration in root were 1.5 times more than shoot. Similar results were obtained for $E$. Crassipes with 3 to 15 time more concentration in roots $[13,18]$. Due to industrial effluent, accumulation of various metal ions and external disturbance might affect the accumulation capacity of the plant [10, 12, 19].

Many researchers have mentioned that the higher concentration of metal ions were accumulated in root than in shoots [18]. Also it is found out that non-essential metal ions had higher TF value than the essential metal ions [20]. And the same has been obtained for the study with non-essential elements ( $\mathrm{Ar}$ an $\mathrm{Pb}$ ) had higher TF value then $\mathrm{Ca}$, Fe and $\mathrm{Zn}$. Even though the TF value were $<1$ for metal ions, plant possess $>0.5$ value for all metal ions and acts as a hyperaccumulator. Although the concentration of Fe ions was higher at initial but had low TF value than other metals. Due to the less availability and low concentration of metal ions such as $\mathrm{Pb}, \mathrm{Ca}, \mathrm{Ar}$ and $\mathrm{Zn}$ were distributed into shoot parts over a large biomass. $\mathrm{Zn}$ and $\mathrm{Ca}$ were found to be more portable but the presence of non-essential metal ions resist their nature. Metal ions were usually accumulated highly in fibrous root plant and the accumulation was justified by $E$. Crassipes after the experimental period [14].

Attraction of aquatic plants towards heavy metal ions were expressed by the bioconcentration factor (BCF), the ratio between plant-metal concentration [21]. Presence of metal ions in effluent and as tailings influences the accumulation ability of the aquatic plant [16]. It is commonly known that metal ion in effluent and BCF value were inverse to each other. Good accumulator plants were documented by two conditions (a) ability to uptake more metal ions in it than in effluent and (b) ability to bioconcentrate the metal ions in its tissues [11]. Various studies by researchers stated that the BCF value of root is always higher than that of shoot [7]. The result obtained from the experiment also justifies with the previous studies [22]. BCF values of root and shoot were high in Ca followed by $\mathrm{Zn}$ and $\mathrm{Fe}$, whereas the value of non-essential element $\mathrm{Ar}$ was the highest and $\mathrm{Pb}$ at the least [23]. The sudden increase in BCF value at later stages indicates that the reduction of contaminant in effluent. It can be understood from the TF and BCF Fig. 2, 3, 4.

Researchers also suggest that the aquatic plant $E$. Crassipes had the ability to remove metal ions from fresh water under low concentrations [23]. But the experiment was not conducted on synthetic effluent and the result obtained by various researchers were not obtained. It indicated that the BCF value increases at low concentration and vice versa. In present study $\mathrm{Ar}$ and $\mathrm{Ca}$ had high $\mathrm{BCF}$ value in roots and shoots than $\mathrm{Zn}$ followed by Fe and $\mathrm{Pb}$. Maximum $\mathrm{BCF}$ values for $\mathrm{Ar}$, $\mathrm{Pb}$, $\mathrm{Ca}, \mathrm{Fe}$ and $\mathrm{Zn}$ in $\mathrm{E}$. Crassipes roots were $1.21,0.37,1.00,0.54$ and 0.65 respectively; while their maximum $\mathrm{BCF}$ values in shoots were $0.69,0.27,0.61,0.27$ and 0.40 respectively. In this experiment, aquatic plant had the ability to concentrate various metal ions to its tissues and acts as very good accumulator [23-26].

Since TrF is a newly formulated one, it is must to understand the relation between contaminated and uncontaminated medium. TrF has a direct effect of metal ions in the contaminated medium and the metal ions accumulated by the plant. It is due to competitive nature of heavy metal ions ready to enter into plants system [27-29]. As most of the metal ions are already accumulated by the plant and the TrF value only increases for a specific period. In general, plant accumulates nutrients in soil through root [30-32]. It is understood that contact of plants root parts and soil was an important factor in the phytoremediation process. Based on the TF, BCF and TrF values of five metal ions from battery industrial effluent, $E$. Crassipes could be used as a phytoremediator.

\section{CONCLUSIONS}

The present study demonstrated that E. Crassipes was a very good accumulator for various elements and can be applicable to treat wastewater from different sources. It is found to be capable of uptake a large amount of HM ions under CDM. Moderate TF and BCF values indicates that the plants were potential phytoextractor. Accumulated HM ions were translocated into shoots but the HM toxicities were balanced in both root and shoots. As TrF value increases at later stage indirectly enhances the BCF value. It is understood that the aquatic plants uptake HM ions more from soil than the water and thus prevents BCF value of HM ions at initial stage. Since E. Crassipes can be used for biogas production, provides a positive result for phytoremedial treatment and CDM is an organic substance, it can be utilized in future for its accumulative capacity of contaminants in water and soils.

Please use a 9-point Arial font, or other Roman font with serifs, as close as possible in appearance to Arial in which these guidelines have been set. The goal is to have a 9-point text, as you see here. Please use sans-serif or non-proportional fonts only for special purposes, such as distinguishing source code text. If Arial is not available, try the font named Computer Modern Roman. On a Macintosh, use the font named Times. Right margins should be justified, not ragged.

\section{ACKNOWLEDGMENTS}

Authors would like to thank The Management, Coimbatore Institute of Technology, Coimbatore for providing adequate space to do the project. Dineshkumar M, would like to acknowledge the TEQIP - Phase II, NPIU for assisting financially. 


\section{REFERENCES}

1. Abdelhafez, A.A., Abbas, M.H.H., Attia, T.M.S., 2015. Environmental Monitoring of Heavy-Metals Status and Human Health Risk Assessment in the soil of Sahl El-Hessania Area, Egypt. Polish J. Environ. Stud. 24, $459-467$.

2. Chen, L., Cai, Q., Xu, S., Liu, X., Chen, S., 2015. Distibution Characteristics, Pollution Assessment, and Source Identification of Heavy Metals in Sediments of Wetland Lakes. Polish J. Environ. Stud. 24, 1525-1533.

3. Singh, A., Prasad, S.M., 2011. Reduction of heavy metal load in food chain: technology assessment. Rev. Environ. Sci. Bio/Technology 10, 199-214. doi:10.1007/s11157-011-9241-z

4. Miloskovic, A., Simic, V., Milošković, A., Simić, V., 2015. Arsenic and Other Trace Elements in Five Edible Fish Species in Relation to Fish Size and Weight and Potential Health Risks for Human Consumption. Polish J. Environ. Stud. 24, 199-206. doi:10.15244/pjoes/24929

5. Özbay, İ., 2015. Evaluation of Municipal Solid Waste Management Practices for an Industrialized City. Polish J. Environ. Stud. 24, 637-644. doi:10.15244/pjoes/30933

6. Przydatek, G., 2016. A Comparative Analysis of Municipal Waste Management Systems. Polish J. Environ. Stud. 25, 2107-2112. doi:10.15244/pjoes/61823

7. Farid, M., Irshad, M., Fawad, M., Ali, Z., Eneji, A.E., Aurangzeb, N., Mohammad, A., Ali, B., 2014. Effect of cyclic phytoremediation with different wetland plants on municipal wastewater. Int. J. Phytoremediation 16, 572-81. doi:10.1080/15226514.2013.798623

8. Çakmakci, T., Ucar, Y., 2014. Efficiency of Canola ( Brassica Napus L .) as an Accumulator of Heavy Metals in Wastewater Applications. Polish J. Environ. Stud. 23, 2309-2313.

9. Zhang, C., Tan, S., Li, J., Peng, C., 2016. Polishing of secondary effluent by a two-stage vertical-flow constructed wetland. Polish J. Environ. Stud. 24, 923-928. doi:10.15244/pjoes/23868

10. Akinbile, C.O., Ogunrinde, T.A., Che bt Man, H., Aziz, H.A., 2016. Phytoremediation of domestic wastewaters in free water surface constructed wetlands using Azolla pinnata. Int. J. Phytoremediation 18, 54-61. doi:10.1080/15226514.2015.1058330

11. Zhang, Z., Rengel, Z., Meney, K., 2010. Cadmium accumulation and translocation in four emergent wetland species. Water. Air. Soil Pollut. 212, 239-249. doi:10.1007/s11270-010-0339-7

12. Pandey, V.C., 2016. Phytoremediation efficiency of Eichhornia crassipes in fly ash pond. Int. J. Phytoremediation 18, 450-452. doi:10.1080/15226514.2015.1109605

13. Rezania, S., Din, M.F.M., Taib, S.M., Dahalan, F.A., Songip, A.R., Singh, L., Kamyab, H., 2016. The efficient role of aquatic plant (water hyacinth) in treating domestic wastewater in continuous system. Int. J. Phytoremediation 18, 679-685. doi:10.1080/15226514.2015.1130018

14. Feng, W., Xiao, K., Zhou, W., Zhu, D., Zhou, Y., Yuan, Y., Xiao, N., Wan, X., Hua, Y., Zhao, J., 2016. Analysis of utilization technologies for Eichhornia crassipes biomass harvested after restoration of wastewater. Bioresour. Technol. doi:10.1016/j.biortech.2016.10.047

15. Sapci, Z., Ustun, E.B., 2015. Heavy Metal Uptakes by Myriophyllum verticillatum from Two Environmental Matrices: The Water and the Sediment. Int. J. Phytoremediation 17, 290-7. doi:10.1080/15226514.2014.898022

16. Ciurli, a., Lenzi, L., Alpi, a., Pardossi, a., 2014. Arsenic Uptake and Translocation by Plants in Pot and Field Experiments. Int. J. Phytoremediation 16, 804-823. doi:10.1080/15226514.2013.856850

17. Farnese, F., Oliveira, J., Lima, Leão, G., Gusman, G., Silva, Lc, 2014. Evaluation of the potential of Pistia stratiotes L. (water lettuce) for bioindication and phytoremediation of aquatic environments contaminated with arsenic. Braz. J. Biol 103, 103-112. doi:10.1590/1519-6984.01113

18. Bernardini, a, Salvatori, E., Guerrini, V., Fusaro, L., Canepari, S., Manes, F., 2015. Effects of high $\mathrm{Zn}$ and $\mathrm{Pb}$ concentrations on Phragmites australis (Cav.) Trin. Ex. Steudel: photosynthetic performance and metal accumulation capacity under controlled conditions. Int. J. Phytoremediation 6514. doi:10.1080/15226514.2015.1058327

19. Bokhari, S.H., Ahmad, I., Mahmood-Ul-Hassan, M., Mohammad, A., 2016. Phytoremediation potential of Lemna minor L. for heavy metals. Int. J. Phytoremediation 18, 25-32. doi:10.1080/15226514.2015.1058331

20. Borisova, G., Chukina, N., Maleva, M., Kumar, A., Prasad, M.N. V., 2016. Thiols as Biomarkers of Heavy Metal Tolerance in the Aquatic Macrophytes of Middle Urals, Russia. Int. J. Phytoremediation 6514, 00-00. doi:10.1080/15226514.2016.1183572

21. Budak, F., Zaimoğlu, Z., Başcı, N., 2011. Uptake and Translocation of Hexavalent Chromium by Selected Species of Ornamental Plants. Polish J. Environmnetal Stud. 20, 857-862.

22. Mahamadi, C., Nharingo, T., 2010. Competitive adsorption of $\mathrm{Pb} 2+, \mathrm{Cd} 2+$ and $\mathrm{Zn} 2+$ ions onto Eichhornia crassipes in binary and ternary systems. Bioresour. Technol. 101, 859-864. doi:10.1016/j.biortech.2009.08.097 
23. Choiński, A., Ptak, M., Ławniczak, A., 2016. Changes in Water Resources of Polish Lakes as Influenced by Natural and Anthropogenic Factors. Polish J. Environ. Stud. 25, 1883-1890. doi:10.15244/pjoes/62906

24. Ciarkowska, K., Hanus-Fajerska, E., 2008. Remediation of Soil-Free grounds contaminated by Zinc, Lead and Cadmium with the use of Metanophytes. Polish J. Environ. Stud. 17, 707-712.

25. Engin, M.S., Uyanik, a, Kutbay, H.G., 2015. Accumulation of heavy metals in water, sediments and wetland plants of kizilirmak delta (samsun, Turkey). Int. J. Phytoremediation 17, 66-75. doi:10.1080/15226514.2013.828019

26. Hazra, M., Avishek, K., Pathak, G., 2015. Phytoremedial Potential of Typha latifolia, Eichornia crassipes and Monochoria hastata found in Contaminated Water Bodies Across Ranchi City (India). Int. J. Phytoremediation 17, 835-840. doi:10.1080/15226514.2014.964847

27. Paun, A., Neagoe, A., Paun, M., Baciu, I., lordache, V., 2015. Heavy Metal-Induced Differential Responses to Oxidative Stress and Protection by Mycorrhization in Sunflowers Grown in Lab and Field Scales. Polish J. Environ. Stud. 24, 1235-1247. doi:10.15244/pjoes/32099

28. Li, Q., Chen, B., Lin, P., Zhou, J., Zhan, J., Shen, Q., Pan, X., 2014. Adsorption of heavy metal from aqueous solution by dehydrated root powder of Long-root Eichhornia crassipes. Int. J. Phytoremediation 00-00. doi:10.1080/15226514.2014.898017

29. Soni, H.B., Thomas, S., 2015. Biotransportation of Heavy Metals in Eichhornia crassipes ( MART .) Solms . Using X-Ray Fluorescence Spectroscopy 10, 9-21.

30. Hill, J.M., 2014. Investigations of growth metrics and $\delta 15 \mathrm{~N}$ values of water hyacinth (Eichhornia crassipes, (Mart.) Solms-Laub) in relation to biological control. Aquat. Bot. 114, 12-20. doi:10.1016/j.aquabot.2013.12.001

31. Parzych, A.E., 2016. Accumulation of chemical elements by organs of Sparganium erectum L. and their potential use in phytoremediation process. J. Ecol. Eng. 17, 89-100. doi:10.12911/22998993/61195

32. Rai, P.K., 2008. Heavy metal pollution in aquatic ecosystems and its phytoremediation using wetland plants: an ecosustainable approach. Int. J. Phytoremediation 10, 131-158. doi:10.1080/15226510801913918

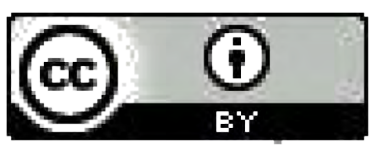

This work is licensed under a Creative Commons Attribution 4.0 International License. 